THE DIRECT CULTIVATION OF TREPONEMA PAL LIDUM PATHOGENIC FOR THE MONKEY.*

\author{
By HIDEYO NOGUCHI, M.D. \\ (From the Laboratories of The Rockefeller Institute for Medical Research, \\ New York.) \\ Plates 12-I4.
}

I have described, in a previous communication, ${ }^{1}$ a method for the cultivation of Treponema pallidum from the testicular lesions of rabbits inoculated with human syphilitic material containing that organism. At that time I had failed to cultivate the pallidum directly from syphilitic lesions in man, a feat that has now been accomplished. In cultivating the organisms from the testicular lesions, $I$ found it advantageous to employ first a fluid medium and later, after adaptation had taken place, to substitute a solid medium. This is a satisfactory method for the testicular lesions which are nearly free from contaminating bacteria, but it is not applicable to the highly contaminated primary lesions in human cases of syphilis.

Two conditions are all-important in the working out of the *method of direct cultivation: first, the maintenance of strict anaerobiosis; and second, the property possessed by the pallida of migrating in the solid medium in which they are multiplying. To meet these conditions, I employed a high cylindrical layer of a solid medium consisting of two parts of 2 per cent. slightly alkaline agar and one part of ascitic or hydrocele fluid, at the bottom of which has been placed a fragment of sterile tissue, such as rabbit kidney or testicle. I have concluded that the tissue acts chiefly by removing the traces of oxygen that exist in the lower levels of the medium, and probably also by providing a special form of nutriment. The solid medium, when inoculated with a fluid containing pallida and bacteria, seems to keep the latter fixed to the inoculation stab while

* Received for publication, November 25, I9I r.

${ }^{1}$ Noguchi, Jour. Exper. Med., I9I I, xiv, 99. 
permitting the pallida to migrate to a distance where they may often be found in a pure or nearly pure state.

Comparisons have been made between the agar medium described and the gelatinized horse serum employed by Schereschewsky, ${ }^{2}$ in favor of the former. The disadvantage of the gelatinized serum arises from the fact that the bacteria rapidly liquify it, and acids render it more permeable for bacteria. Hence it is very difficult to separate the spirochætæ from the contaminating bacteria.

DIRECT ISOLATION OF THE PALLIDUM.

Fifteen cubic centimeters of the medium described are placed into test-tubes measuring two by twenty centimeters. At the bottom is placed a fragment of sterile tissue. While rabbit kidney or testicle is preferable, human placenta, sheep testicle, or other sterile organ will suffice. The medium is prepared in the tubes, after the addition of the tissue, by mixing two parts of the melted agar at $50^{\circ} \mathrm{C}$. and one part of ascitic or hydrocele fluid. After solidification, a layer of sterile paraffin oil three centimeters deep is added to prevent evaporation of the medium. A considerable number of tubes should be prepared at a time, and they should be incubated for a few days prior to inóculation, to determine sterility.

The material to be cultivated is obtained from lesions rich in the pallidum, such as chancre, condyloma, or skin papule, from which are snipped off, after cleaning with sterile salt solution, suitable fragments. These are immersed immediately into sterile salt solution containing in addition I per cent. sodium citrate. The fragment of tissue, which should be carefully preserved against drying, is then cut into small bits which are used as follows: one bit is emulsified in a mortar with the citrate solution; the others are inserted as such into tubes of culture medium, provided the emulsion shows, under the dark-field microscope, the presence of the pallidum.

Each of the half dozen bits of pallidum-containing tissue is inserted into a tube of the ascitic fluid tissue agar by being forced to the bottom by means of a thin blunt glass rod or heavy platinum loop, and into the same tube several drops of the emulsion are introduced by a capillary pipette also inserted deeply into the medium.

'Schereschewsky, Deutsch. med. Wchnschr., I909, xxxv, 835, I260. 
Care is taken to avoid tearing the medium, and about six tubes are inoculated from each specimen of tissue.

The tubes should be incubated at $37^{\circ} \mathrm{C}$. constantly for two to three weeks before examination.

The inoculated tubes usually become diffusely opalescent and show, as well, a dense opaque growth of bacteria along the stabcanal and about the wall of the tube. When considerable gas is formed, the medium is torn. The cultures are now punctured in several places with a capillary pipette which is inserted deeply into the tube, and the withdrawn contents are examined under the darkfield. The rule is to find large numbers of the pallidum imbedded in the agar and hence immotile. Should the organisms be present in a space clear of agar, they show active motility. Bacteria are always mingled at this stage with the pallidum.

The impure culture is fetid and putrefactive. Purification is begun by inoculating about twelve tubes with the impure culture by means of a charged capillary pipette that is carefully inserted in the centre of the agar column quite to the bottom of the tube. The contents of the pipette are expressed by means of compressed air, for which purpose I employ a syringe. The medium must not be split. The inoculated tubes are again incubated at $37^{\circ} \mathrm{C}$. for two or three weeks. The bacteria grow in a dense mass along the stabcanal and on the surface of the medium. The tubes are inspected, from time to time, and in some a faint hazy zone will be seen to radiate from the stab-canal towards the sides of the tube. This hazy appearance is caused, usually, by masses of the pallidum that are growing away from the bacteria. When this growth has spread sufficiently far away from the stab-canal another transfer is made.

The surface of medium is sterilized with sublimate alcohol that is poured away. The tube is marked about the middle with a diamond pencil, and to the cut a pointed red-hot glass rod is applied. The tube cracks and the upper half is removed. The exposed surface of agar is sterilized with sublimate alcohol, after which the remaining moisture is wiped away with sterile absorbent gauze. By gently bending the agar column, it cracks transversely and exposes a clear surface on which the hazy growth is readily seen. Now, without touching the central canal, a capillary pipette is introduced into the 
haze and, after confirming, by dark-field examination, that it is caused by the presence of the pallidum, a series of inoculations are made in the manner described. It happens rarely that a pure culture is obtained on the first or second reinoculation; usually several reinoculations are required.

Not infrequently the growths of the pallidum are almost invisible. I am inclined to think that this is due to the quality of the culture medium. In this case, the dark-field microscope is the only reliable guide as to growth and situation in the culture of the pallidum. Again, the bacteria in the stab-canal may produce so much acid that it diffuses into the surrounding layer of medium where it causes a haziness capable of being mistaken for growth.

When ascitic or hydrocele fluid is not available, serum from the horse or sheep may be used for the purification process; they are, however, less satisfactory than the former fluids. It should be stated that $I$ have found some specimens of ascitic fluid entirely unsuitable to the cultivation of the pallidum. When a favorable specimen has been obtained, it should be stored in sterile condition for future use.

PROPERTIES OF THE PURE CULTURES.

The pure cultures of the pallidum that $I$ have studied have shown certain distinctive properties. First, the colonies of the pallidum that diffuse into the medium are never sharply, but always faintly visible, and the degree of visibility tends to be less in the pure than in the impure state. It. seems to be unusual for the colonies to become discrete, although this has been observed when the sample of ascitic fluid has been very favorable. Second, the growth is most marked about the fragment of sterile tissue; I have not thus far succeeded in obtaining growth without fragments of tissue, although the medium used was similar in all other respects. In this important respect, the organisms that $I$ have cultivated differ from those described by Mühlens ${ }^{3}$ and by Hoffmann, ${ }^{4}$ who obtained growth in a medium devoid of tissue. I have never observed my growths to cause any coagulation of the serum in a fluid medium, or to produce

'Mühlens, Klin. Jahrb., I9Io, xxiii, 339.

'Hoffmann, Ztschr. f. Hyg. u. Infektionskrankh., I9I1, 1xviii, 27. 
putrefactive odors, both of which are noted to occur by Mühlens and by Hoffmann.

When the medium is favorable, the first indications of growth appear in about seventy-two hours, and these increase gradually for two or three weeks, when the growth is at its height. The growth in a fluid medium takes place very slowly but continues for many weeks. The medium retains its fluid state indefinitely.

Morphology.-In young cultures, the greater part of the spirochætæ are short and actively motile. After growing for about two weeks, they attain the usual length of eight to twelve curves. Active motility is continued and the typical cork-screw movement is displayed. When the organisms are imbedded in the agar medium, they are immotilized. After several weeks, not only is the motility reduced, but the length has been increased (figures $I, 2,3$, and 5 ). The ends of the mature pallidum often show fine flagellum-like prolongations which are frequently perfectly curved, although sometimes they are devoid of curves (figure 6). The typical morphological characters are subject to disturbance by violent handling, as by the careless introduction into the growing mass of the capillary pipette or the presence of a trace of oxygen. Then the curves appear irregular, and straight forms occur. When irregular and atypical spirochætæ appear in certain tubes, they are due to the medium which is not strictly suitable, or to the presence of a trace of oxygen. To secure perfect and typical cultures, optimum conditions must be supplied.

Multiplication.-Schaudinn ${ }^{5}$ described longitudinal division of the pallidum which he observed in two specimens. However, later investigators have described transverse division of the organism. It is important to ascertain which is the primary, or normal, and which the secondary, or abnormal, mode of division. That appearances suggesting both longitudinal splitting and transverse division are observable is admitted: the question relates to the significance of each process. Those who regard the longitudinal process as the normal one for multiplication look upon the transverse process as a last stage in the series of changes; while those who regard the transverse process as the normal one look upon the appearance of

'Schaudinn, Arb. a. d. k. Gsndhtsamte., Ig07, xxvi, II. 
longitudinal splitting as caused by the coiling of one spiral organism, still united by a thin end filament, about another part of the same organism which is undergoing transverse division.

The disputed points relate to unstained and stained preparations directly obtained from lesions in man or animals in which the possibility of artefacts can hardly be removed. In both cases, the conditions are not distinctly favorable. What is demanded are periods of development of the pallidum during the stage of active division, and this is provided in the pure cultivation at certain stages of growth. I have now studied about ten strains at various stages of proliferation and growth and under varying conditions of cultivation, so that $I$ have formed an objective conception of the process.

The mode of division of the pallidum in pure cultures is such as to admit of ready following of the phenomenon under the darkfield microscope. During the period of active proliferation, numerous dividing individuals may be seen in a single field. Several classes may be constructed according to the stage of the process (figures $7,8,9$, and 10 ): (a) the body is divided at about two thirds of its entire length; $(b)$ the body is completely divided and one part is wrapped about the other with regular curves or flat waves; $(c)$ one half the body is divided and the other not, and the divided half has separated widely so as to produce a figure $\mathrm{Y} ;(d)$ the partially divided body diverges at angles to produce $V$ forms of varying width. When an acute angle is formed, tenuous protoplasmic bridges may span the interval; $(e)$ two bodies remain united by a thin filament, one of which may be of normal or abnormal form; $(f)$ three or more individuals may be united in a series of fine filaments suggesting imperfect transverse segmentation; $(g)$ finally, two blunt wavy individuals each about double the thickness of an ordinary pallidum may remain together (figures I I, I2, I3, I4, and I $_{5}$ ). This last form differs from the others in possessing a few granules that are definitely arranged and aggregated into bands that run across the organism. Whether this condition is degenerative remains to be determined. The longitudinal form of division is met with in all the cultures irrespective of the length of the spirochætæ. During the dividing process, the curves may be shallow and merely wavy; but after the separation is accomplished, the curves 
become deeper and regular. Motility is preserved during division, but is perhaps less active (figure $I 8, A, B$, and C).

The various phases and varieties of the dividing process here described can best be followed when the spirochætæ are embedded at first in the agar medium that is pressed beneath the cover glass without disturbing their position. When the specimens are then liberated into a free space in which a fluid exists, the various phases can be readily traced as they pass from one to another, and in general in the order given, of the series described. Speaking broadly, the process is not rapid and requires about two hours for completion. The final result is two symmetrical halves, although asymmetrical division has been observed in rare instances.

\section{PATHOGENIC PROPERTIES.}

Treponema pallidum is a pathogenic organism. While its natural host is man, it is capable of implantation upon several higher animals, notably upon the monkey and the rabbit. I have already reported the successful inoculation of pure cultures of the pallidum, obtained from the testicular lesions of rabbits, to the testicles of normal rabbits. ${ }^{6}$ Hoffmann ${ }^{7}$ reported somewhat later the successful production of a specific orchitis by inoculating a pure culture derived immediately from human tissues. There is no real difference in these results, since originally all strains of the pallidum are human in origin. On the other hand, not all strains of the spirochætæ can be successfully implanted upon rabbits or other animals, when obtained directly from syphilitic lesions in man. Racial differences exist naturally, and probably can be produced artificially. The pallidum strains which I cultivated from the testicular lesions of rabbits and which were pathogenic for these animals, failed to produce skin lesions when inoculated into monkeys. But the strains described in this paper have been inoculated successfully into the skin of several monkeys.

In the expetimental results to be reported, I employed three cultures of the pallidum derived from as many different human cases of syphilis and two species of lower monkeys, Macacus rhesus and

- Noguchi, Jour. Am. Med. Assn., I91 I, 1vii, I02; Jour. Exper. Med., loc. cit.

'Hoffmann, Deutsch. med. Wchnschr., I9I 1, xxxvii, I546. 
Cercopithecus callitrichus. The inoculations were made by applying ten day old pure cultures in ascitic fluid tissue agar to the freshly shaven, scarified surface of the skin over the eyebrows, and, also, to the scarified prepuce, scrotum, or labia. The cultures were smeared over the prepared surface, and several small injections were made with a very fine syringe. The final results of the inoculations cannot be stated yet, but the present conditions are given in the following protocols.

\section{PROTOCOLS.}

Macacus rhesus, A.-October 2, Igri. A ten day old pure culture of pallidum, strain No. 7 (from a chancre), was inoculated to both eyebrows and the left labium.

October 9. The traumatic reactions have all disappeared.

October 15. Several small nodules appeared on both eyebrows, and a peasized induration at the site of inoculation on the labium.

October 22. The small nodules still persist, and in some there is an increase in size; some are scaly and congested. No pallida are seen in the expressed juice. The labium is still indurated.

October 29. Two distinctly indurated nodules on the left, and one small one on the right eyebrow. On examination of the expressed juice under the darkfield, some active pallida are found. The nodule on the labium shows no pallida.

November 6. The indurated nodules on the eyebrows show superficial ulceration. The expressed juice contains numerous active pallida. The labium is stiil indurated, but no pallida are found.

November II. The size of the nodules on both brows is increasing, showing a moderate degree of congestion. The labium shows only a slight induration. Photographed. The blood gives a positive Wassermann reaction (figures I6 and 17 ).

Macacus rhesus, B.-October 2, I9II. Inoculation made as above with the same culture.

October 9. The traumatic reactions have disappeared.

October 15. Several small indurations on the eyebrows. The skin of the scrotum shows marked induration at the site of inoculation.

October 22. The size of the nodules is increasing.

October 25. Death due to pulmonary tuberculosis. The indurated tissues were excised and examined for the pallida, but none were found.

Macacus rhesus, C.-October 2, I9II. Inoculation made as in monkey B. October 9. The traumatic reactions have disappeared.

October 15. One nodule on the left, and three small nodules on the right eyebrow. The labium is moderately indurated.

October 29. The nodules on the eyebrows have become larger and congested. The labium is indurated.

October 3I. Death from pulmonary tuberculosis. Examination of the indurated tissues from the eyebrows shows numerous pallida.

Macacus rhesus, D.-October 2, I9I I. A ten day old pure culture of pallidum, strain No. 8 (from a condyloma), was used for the inoculation. 
October 9. The traumatic reactions have all disappeared.

October 15. Several small indurations on both eyebrows. The labium shows marked induration at the site of inoculation.

October 22. No further changes.

October 29. The nodules are somewhat larger and fewer in number. The induration of the labium is still about the same. The expressed juice of the nodules on the brows shows a small number of active pallida.

November II. The nodules are becoming smaller in size, and the labium is healing up. No pallida.

Macacus rhesus, E.-October 2, I9II. Inoculation as above.

October 9. All traumatic reactions have disappeared.

October I5. No change.

October 22. No induration.

October 29. No change.

November II. Still no change.

Macacus rhesus, F.-October 2, I9I. Inoculation with a ten day old pure culture of pallidum, strain No. 9 (from a rectal condyloma).

October 9. The eyebrows are smooth and show no induration.

October I5. Several small indurations on the eyebrows.

October 22. The nodules are disappearing.

October 29. The nodules have disappeared.

November 10. No further change.

November II. Death from pulmonary tuberculosis.

Cercopithecus callitrichus, G.-October 2, 19II. Inoculations with the same culture as in monkey $\mathrm{F}$.

October 9. The eyebrows are clean.

October I5. There are several small nodules on both brows.

October 22. The nodules are increasing in size.

October 29. A distinctly raised nodule is seen near the corner of the left eyebrow. The small nodules are disappearing.

November 6. The nodule on the left brow has become very much congested and covered with a scaly crust. Under the crust, the nodule is barely covered with a new epidermis, which by slight scraping caused exudation of a clear serous fluid. Examination of the exudate showed a few active pallida.

November II. The nodule is still much indurated and congested, but the surface is well covered. By gentle scraping, a serous exudate containing pallida escapes from the nodule. The blood gives a positive Wassermann reaction. Photographed.

From these results it can be inferred that pure cultures of Treponema pallidum are capable of causing, in certain lower species of the monkey, lesions of a characteristic form and history that resemble the lesions caused by inoculations of the spirochætæ-containing serum from a primary syphilitic lesion. Coincidentally, the development of the Wassermann reaction in the successfully inoculated monkeys has been observed. 
CONCLUSIONS.

A method for the direct cultivation of Treponema pallidum from human syphilitic lesions, by the employment of a solid medium, has been described. By means of it, three of the four strains worked with were successfully cultivated.

The several pure cultures agree in morphological and cultural characters, grow only in the presence of sterile tissue under anaerobic conditions, and do not produce putrefactive odors. The morphology is typical under optimum cultural conditions; it becomes atypical when the conditions are unfavorable.

In cultures, Treponema pallidum multiplies by longitudinal division. The process is usually symmetrical but occasionally appears to be asymmetrical.

Inoculation of the pure cultures into the skin of two species of lower monkeys was followed by the production of lesions resembling the primary syphilitic lesion occurring in man and those caused in the monkey by inoculation of spirochætæ-containing serum from human sources.

During the course of the positive inoculation in the monkey, the blood develops the property of giving a positive Wassermann reaction. Thus the relation of Treponema pallidum to this reaction is supported, and the identity of the cultivated strains with the species found in human syphilitic lesions established.

\section{EXPLANATION OF PLATES.}

Plate I2.

FIG. I. Treponemata pallida from a young pure culture in an ascitic agar tissue medium, four days old at $37^{\circ} \mathrm{C}$. Dark-field. $\times 1,400$.

FIGS. 2 and 3 . The same after two weeks.

FIG. 4. Treponemata pallida from a chancre. (For comparison.) $\times 1,400$.

FIG. 5. Treponemata pallida from a pure culture in an ascitic agar tissue medium, two weeks at $37^{\circ} \mathrm{C}$. The pallida in free space show typical morphology.

FIG. 6. A short pallidum with flagella-like projections at both ends. $\times I, 400$.

FIGS. 7, 8, 9, and ro. An ascitic agar tissue culture (pure) showing various phases of longitudinal division. $\times 1,400$.

Plate 13.

FIG. II. A mass of dividing pallida from a pure culture in solid media. $\times I, 400$. Figs. 12 and 13 . Peculiar forms of dividing pallida from a pure culture in solid media. $\times 1,400$. 
FIGS. I4 and 15. Dividing forms of pallida in fluid cultures.

FIg. I6. Macacus rhesus, $A$, with primary indurations on the skin above the eyebrows produced with a pure culture of the pallida. Photographed after forty days.

FIG, 17. A pallidum in the expressed juice of the lesions of the same monkey.

$$
\text { Plate I4. }
$$

FIG. 18. A schematic reproduction of different phases of longitudinal division of Treponemata pallida in solid culture (pure). The drawings were made from observations on living organisms under the dark-field microscope. The description of these forms will be found in the text.

$A=$ symmetrical division; $B=$ asymmetrical division; $C=$ irregular forms. 

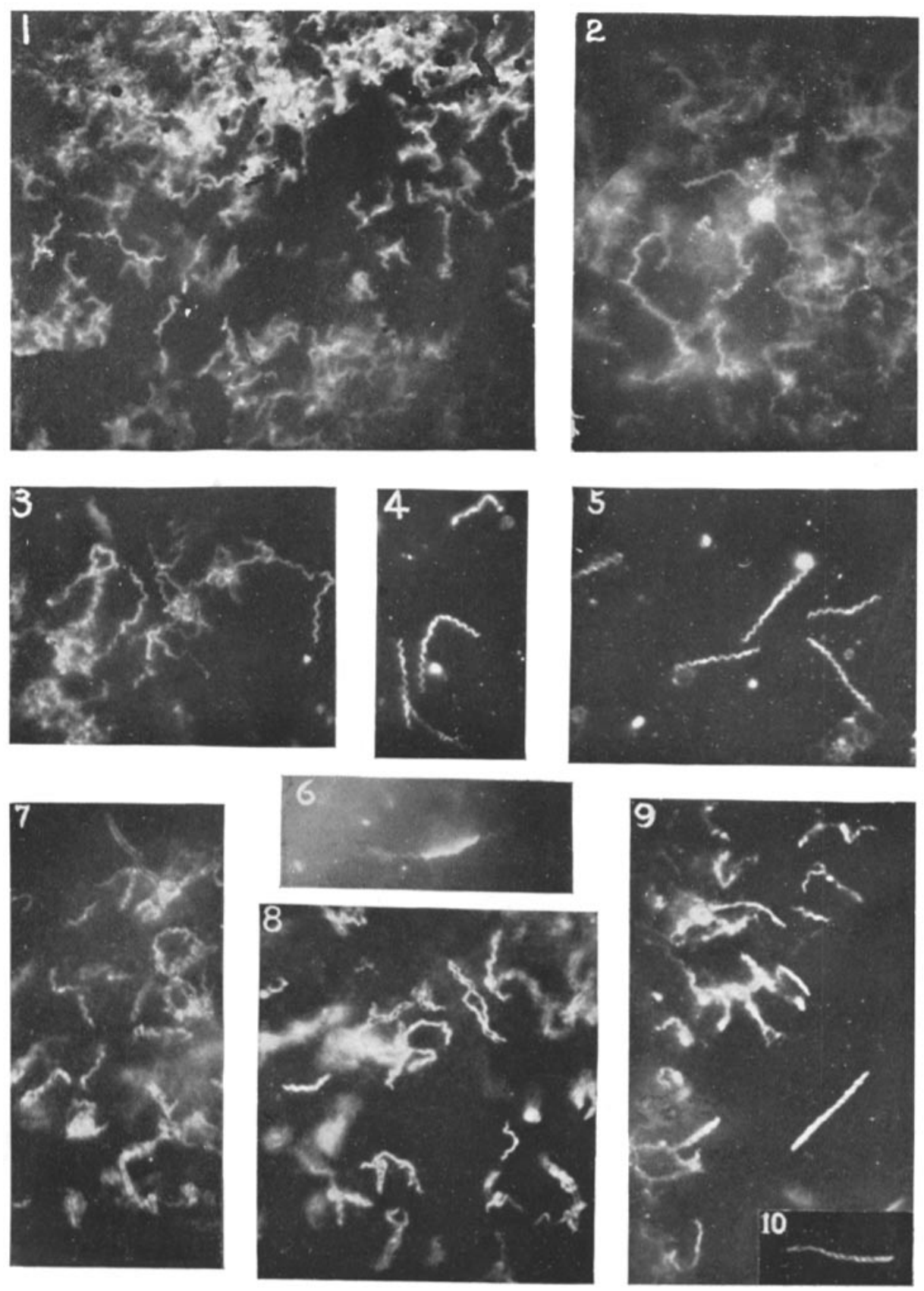
THE JOURNAL OF EXPERIMENTAL MEDICINE VOL. XV.

plate 13.
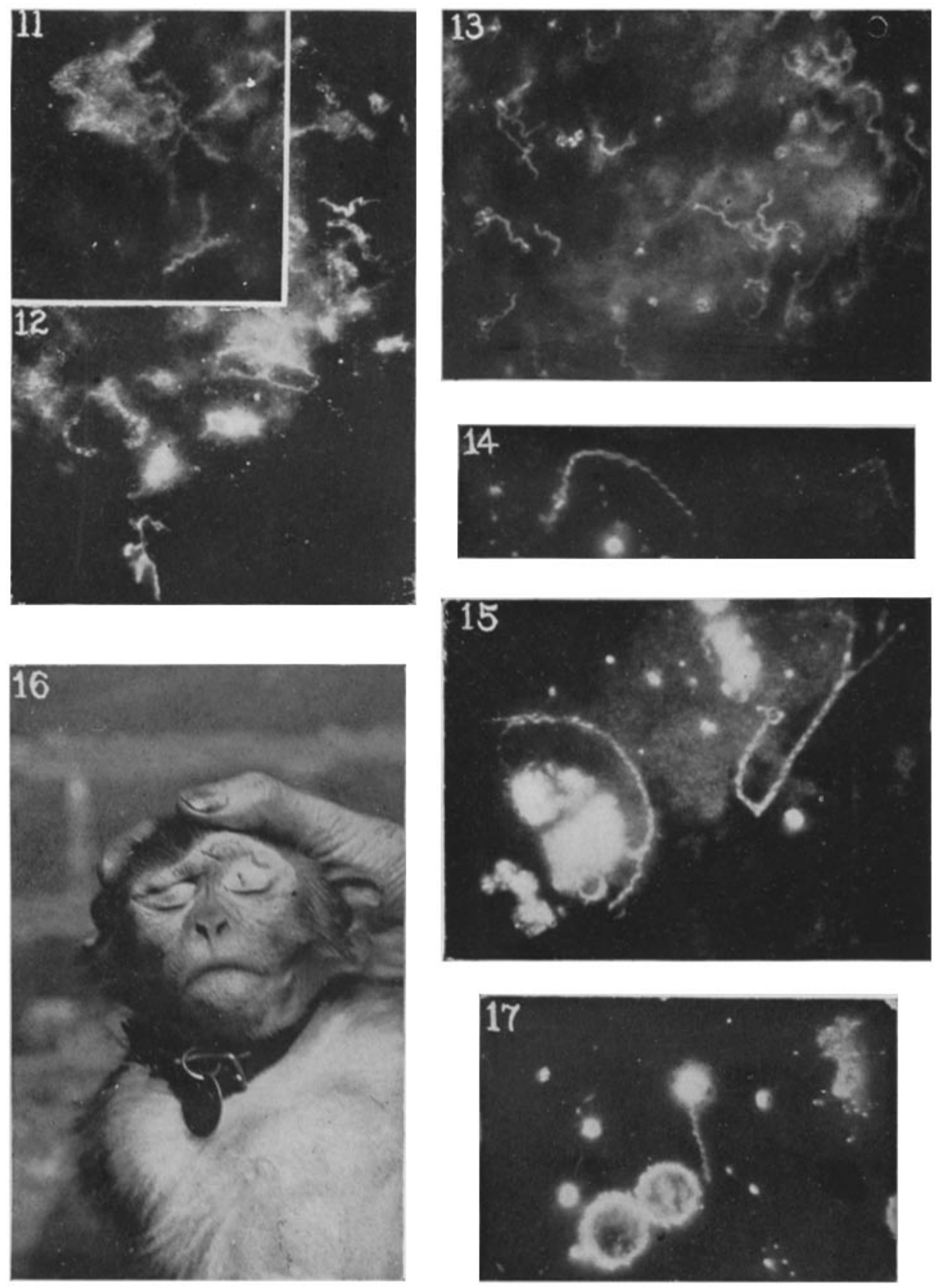
THE JOURNAL OF EXPERIMENTAL MEDICINE VOL. XV.

PLATE 14.

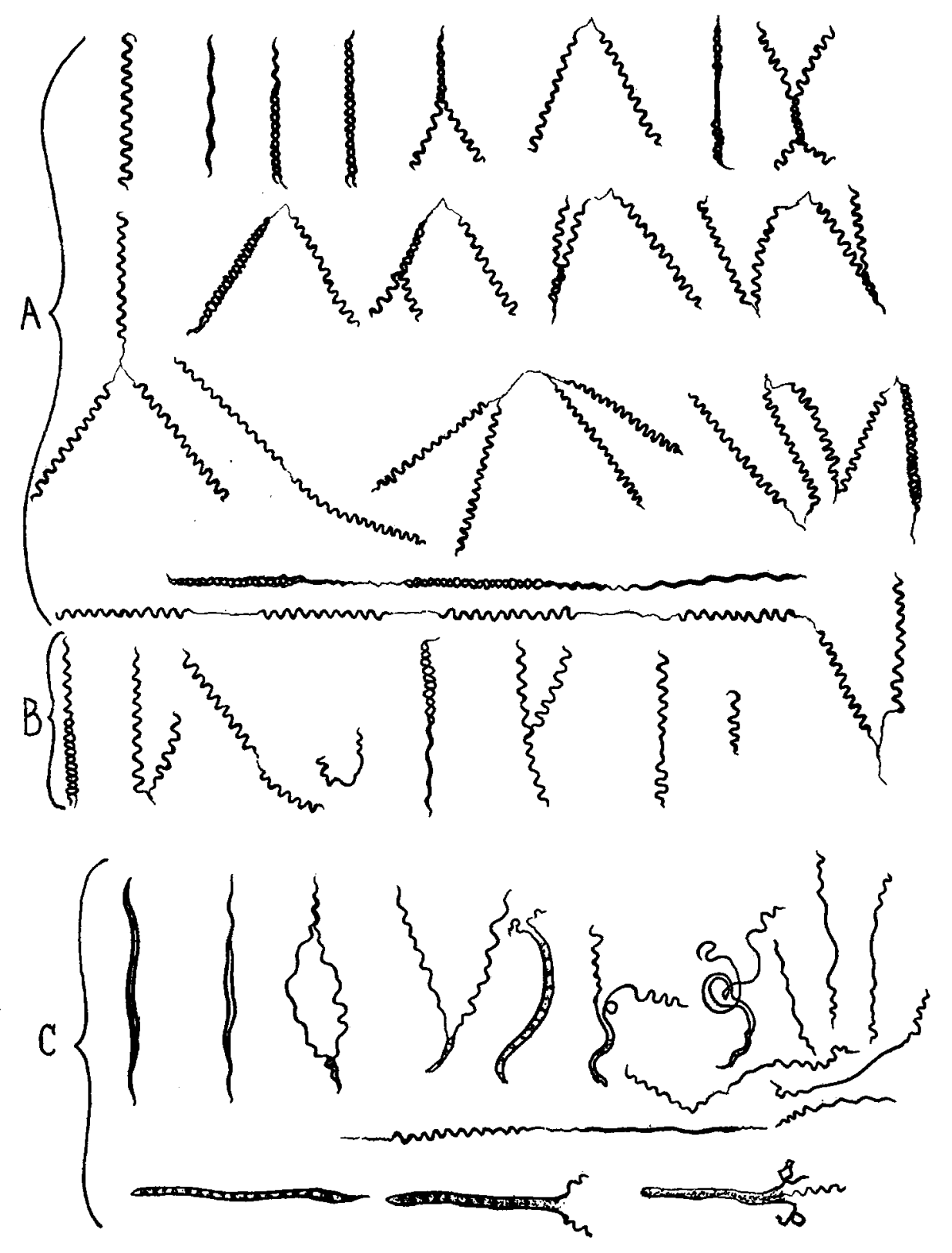

